\title{
Rare by Natural Selection: Disulfide-bonded Supramolecular Antimicrobial Peptides
}

Yizhaq Engelberg ${ }^{1}$, Peleg Ragonis-Bachar ${ }^{1}$, and Meytal Landau ${ }^{1,2, *}$

1Department of Biology, Technion-Israel Institute of Technology, Haifa 3200003, Israel.

2 European Molecular Biology Laboratory (EMBL), Hamburg 22607, Germany.

Corresponding author: mlandau@technion.ac.il

\section{Supplementary Figures and Tables}

Figure S1. Packing and interaction network within the fibrillar assembly of the hLL37 ${ }_{17-}$ ${ }_{29}$ I24C mutant

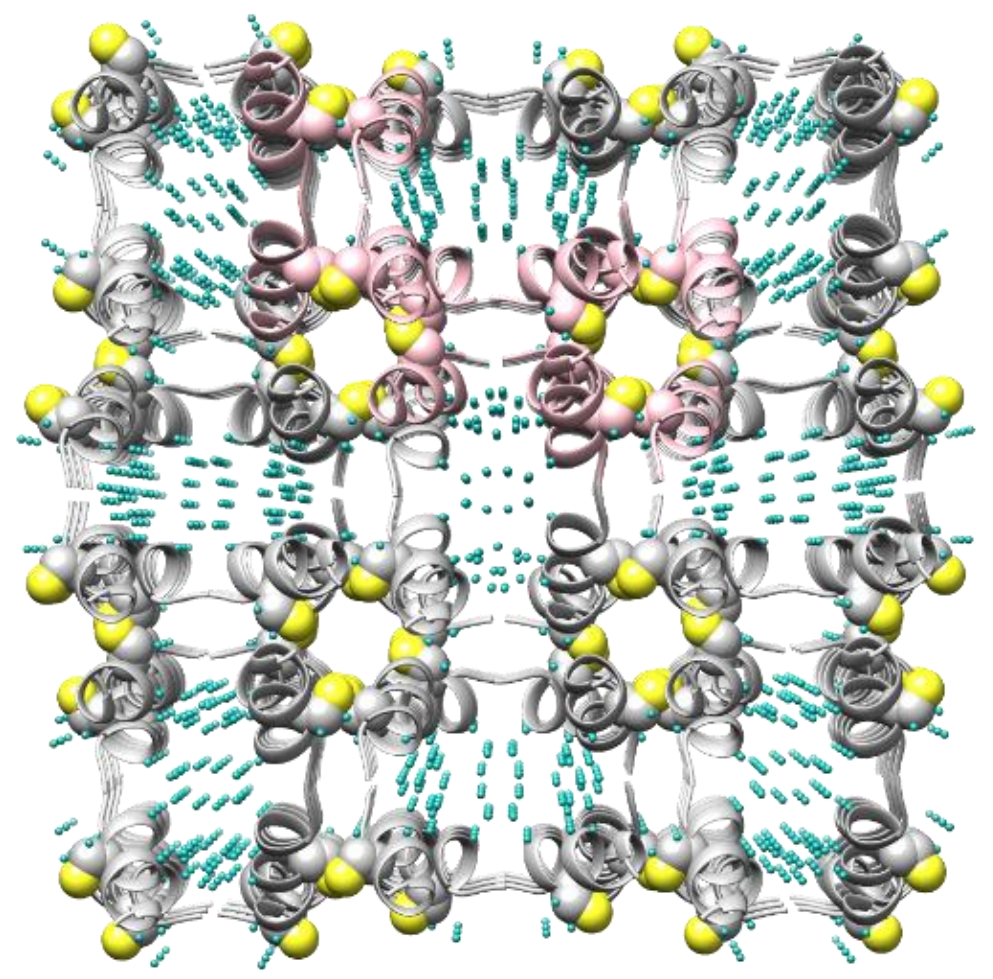

Top-view down the fibril axis of the crystal packing of the hLL3717-29 I24C mutant. The helices are shown as ribbons, colored grey, except for six dimers that are zoomed-into in Figure S4, which are colored pink. Water molecules are presented as cyan balls. Cysteine residues are presented as space-filled atoms with non-carbon atoms colored by atom type (sulfur in yellow). 
Figure S2. Structural comparison of the disulfide-bonded hLL37 ${ }_{17-29}$ I24C mutant dimer and the hLL37 ${ }_{17-29}$ four-helix bundle

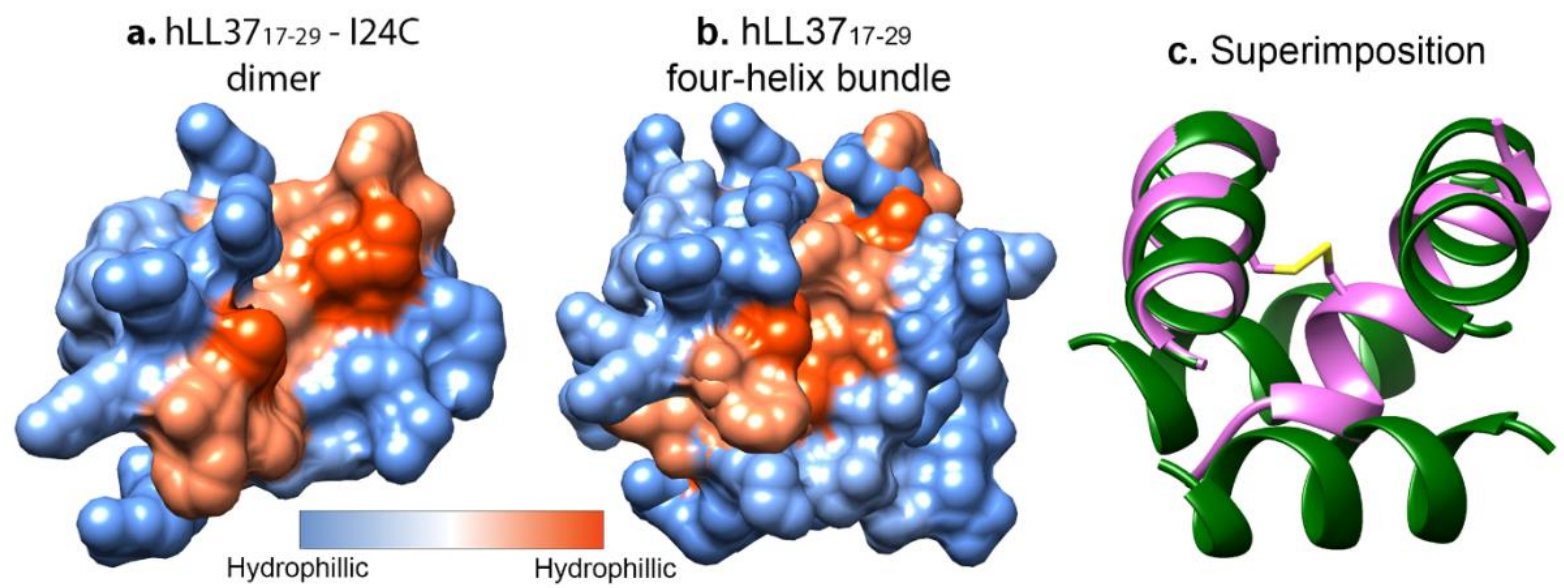

Structural comparison of the covalent dimer of the hLL37 ${ }_{17-29}$ I24C mutant and the four-helix bundle of hLL37 ${ }_{17-29}$, the potential basic unit of the fibril. (a-b) The I24C mutant dimer (a) and the four-helix bundle of hLL37 $17-29$ (b) are shown in a surface representation colored by hydrophobicity according to the scale bar. (c) Superimposition of the $124 \mathrm{C}$ dimer and of hLL37 ${ }_{17-29}$, presented as ribbons colored in magenta and dark green, respectively, shown in the same orientation as in panels a-b. Cysteine residues are shown as sticks and colored by atom type with sulfur in yellow. 
Figure S3. The disulfide-bonded helical dimers of the hLL-37 17-29 I24C mutant further assemble via a network of polar interactions

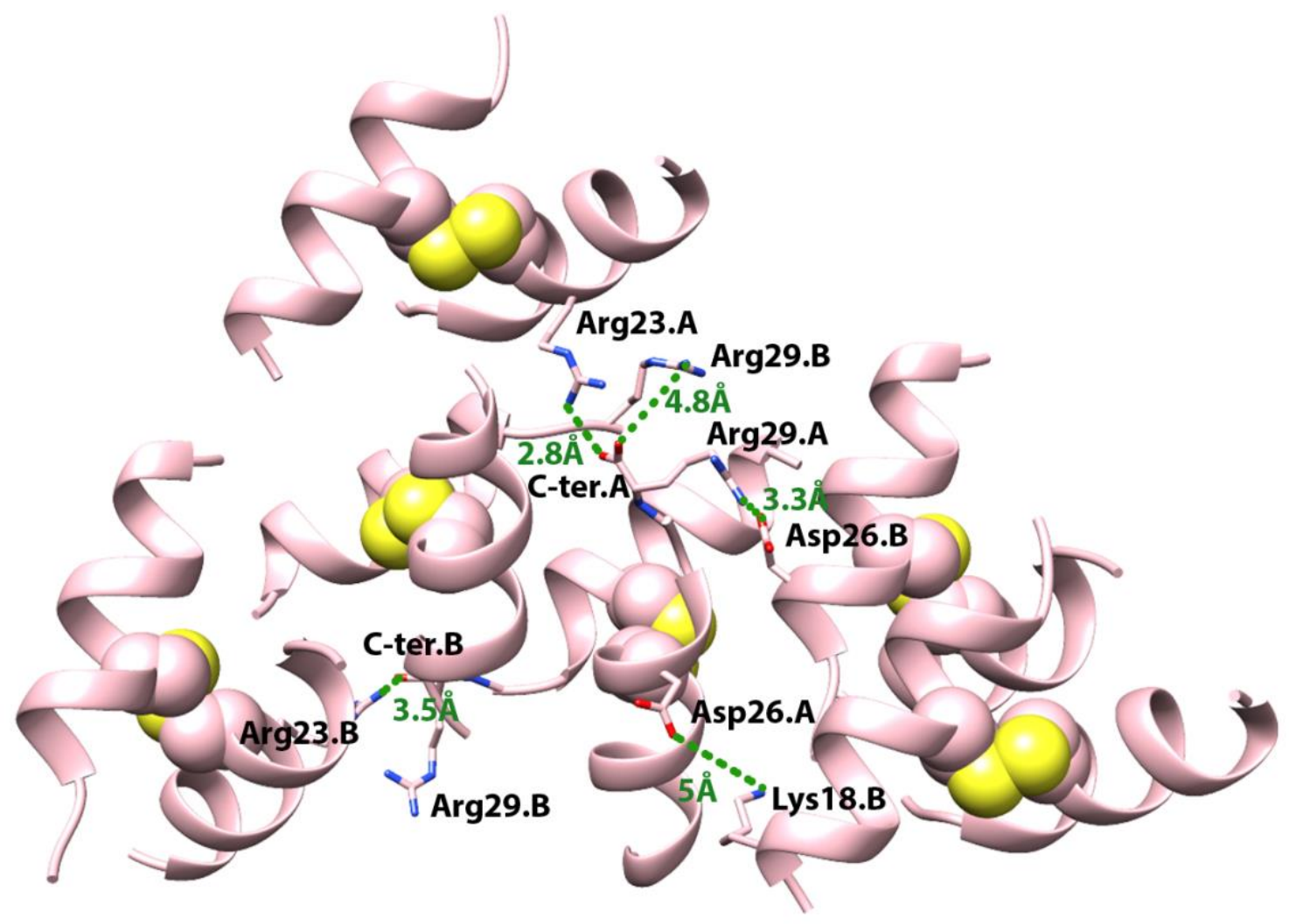

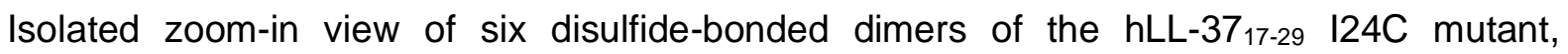
corresponding to the pink-colored helices in Figure S2, and display of a network of putative inter-helical salt bridges. Helices are shown as pink ribbons with cysteine residues presented as space-filled atoms and specific residues involved in the polar network are shown as sticks. Non-carbon atoms are colored by atom type (oxygen in red, nitrogen in blue and sulfur in yellow). Green dashed lines indicate putative salt bridges and their distances. This includes putative salt bridges between Asp26 on chain A in one dimer and Lys18 on chain B of an adjacent dimer, and between Asp26 on chain B and Arg29 of chain A of an adjacent helix. In addition, the carboxyl group of the $\mathrm{C}$ terminus of chain $\mathrm{A}$ formed putative salt bridges with the side chain of Arg23 of chain A of another dimer and with the side chain of Arg29 from chain B of a third dimer. The carboxyl group of the $C$ terminus of chain $B$ formed putative salt bridges with the side chain of Arg23 of chain B of a fourth dimer. Each of the putative inter-dimeric bonds is displayed only once, although it is doubled for reciprocal chains in the dimers. 
Figure S4. Positively charged electrostatic surface of the fibril assembly

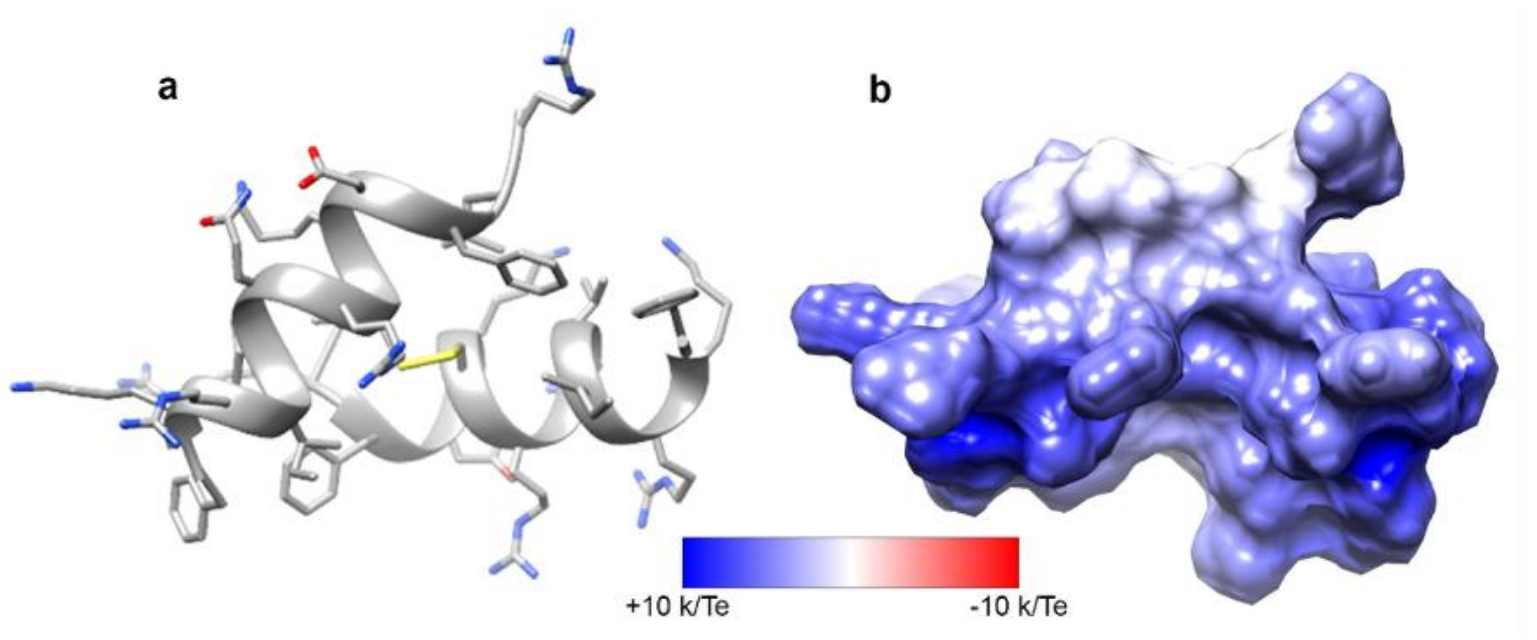

(a) The covalent hLL37 ${ }_{17-29}$ I24C mutant dimer, shown in a grey ribbon presentation, with side chains represented as sticks, and non-carbon atoms colored by atom type (oxygen in red, nitrogen in blue, and sulfur in yellow). (b) A projection of the electrostatic potential $(\varphi)$ onto the molecular surface of the dimer, in the same orientation as in panel a. The scale bar indicates $\varphi$ ranges between $-10 \mathrm{kT} / \mathrm{e}$ (dark red) and $10 \mathrm{kT} / \mathrm{e}$ (dark blue). 
Figure S5. DTT sensitivity of the $M$. Iuteus inhibitory effect of hLL37 $7_{17-29}$ cysteine mutants

$\square 50 \mu \mathrm{M} \quad \square 25 \mu \mathrm{M} \quad \square 5 \mu \mathrm{M} \quad \square 50 \mu \mathrm{M}+\mathrm{x} 10$ DTT $\square 25 \mu \mathrm{M}+\mathrm{x} 10$ DTT $\quad \square 5 \mu \mathrm{M}+\mathrm{x} 10$ DTT

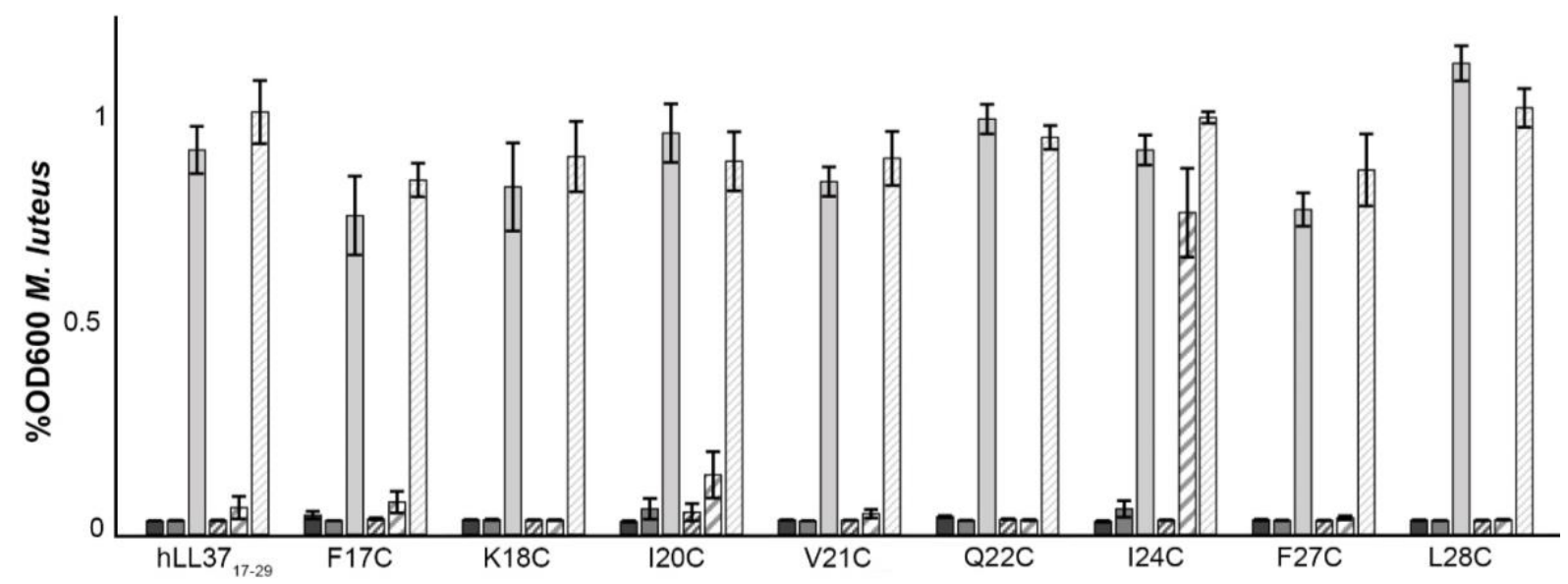

The effect of hLL-37 $17-29$ and its cysteine substitution mutants on M. luteus bacterial growth was tested in the presence and absence of DTT. Bars show the ratio of $M$. luteus growth in the presence of the indicated peptide $(50 \mu \mathrm{M}, 25 \mu \mathrm{M}$ or $5 \mu \mathrm{M})$, compared to the bacterial growth with everything but the peptide. DTT was added at x10 molar ratio compared to peptide concentration. The experiments were performed at least three times, each on a different day. Error bars represent the standard deviation of the mean of the averaged triplicates of all biological repeats. 
Figure S6. DTT sensitivity of the $S$. hominis inhibitory effect of hLL37 $7_{17-29}$ cysteine mutants

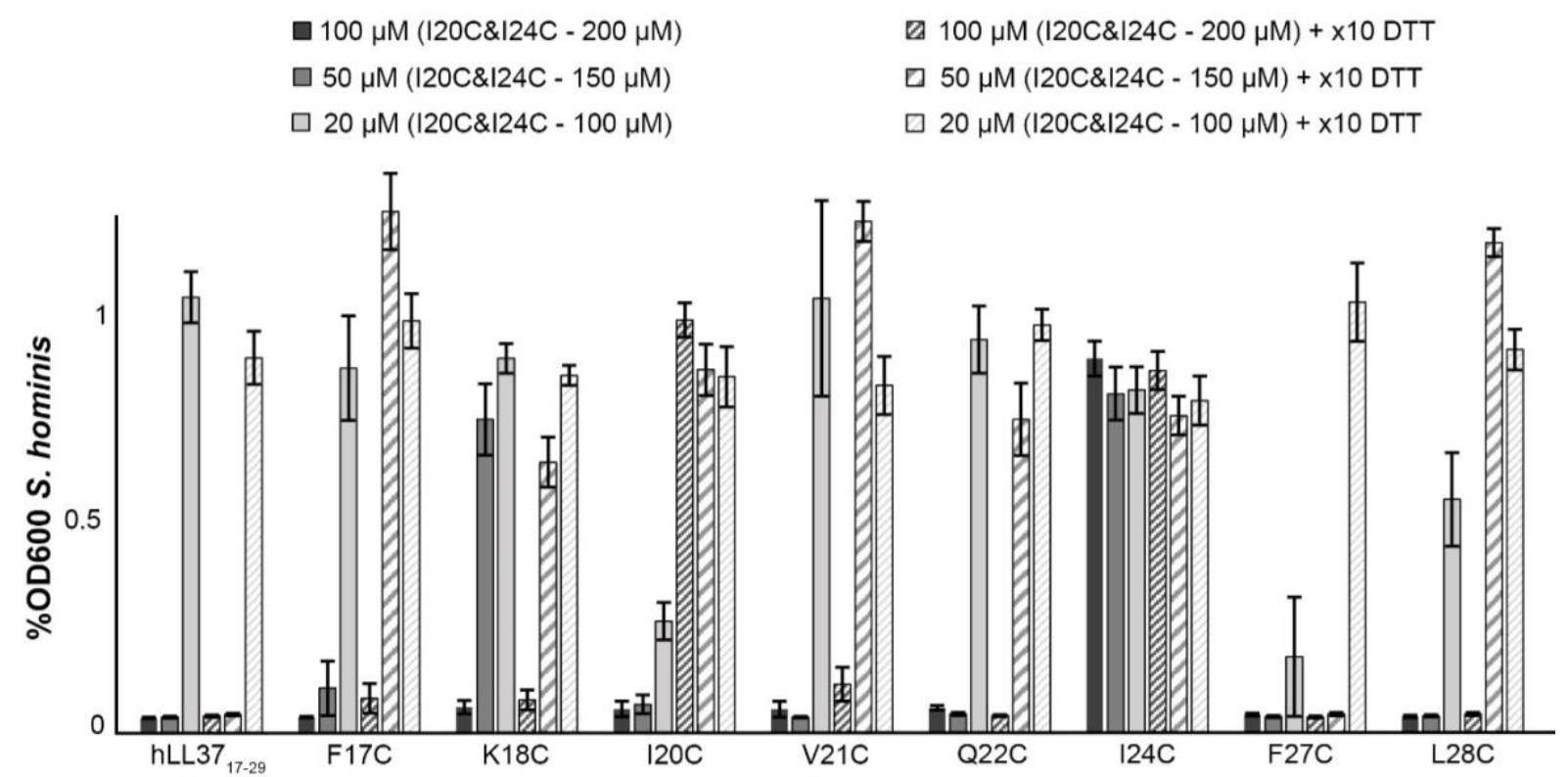

The effect of hLL-37 ${ }_{17-29}$ and its cysteine substitution mutants on S. hominis bacterial growth, was tested in the presence and absence of DTT. Bars show the ratio of $S$. hominis growth in the presence of the indicated peptide $(100 \mu \mathrm{M}, 50 \mu \mathrm{M}$ and $20 \mu \mathrm{M})$, compared to the bacterial growth with everything but the peptide. The I20C and I24C mutants were tested at the following concentrations: $200 \mu \mathrm{M}, 150 \mu \mathrm{M}$ and $100 \mu \mathrm{M}$. DTT was added at x10 molar ratio compared to peptide concentration. The experiments were performed at least four times, each on a different day. Error bars represent the standard deviation of the mean of the averaged triplicates of all biological repeats. 
Figure S7. DTT sensitivity of $E$. coli inhibitory effect of hLL37 ${ }_{17-29}$ cysteine mutants

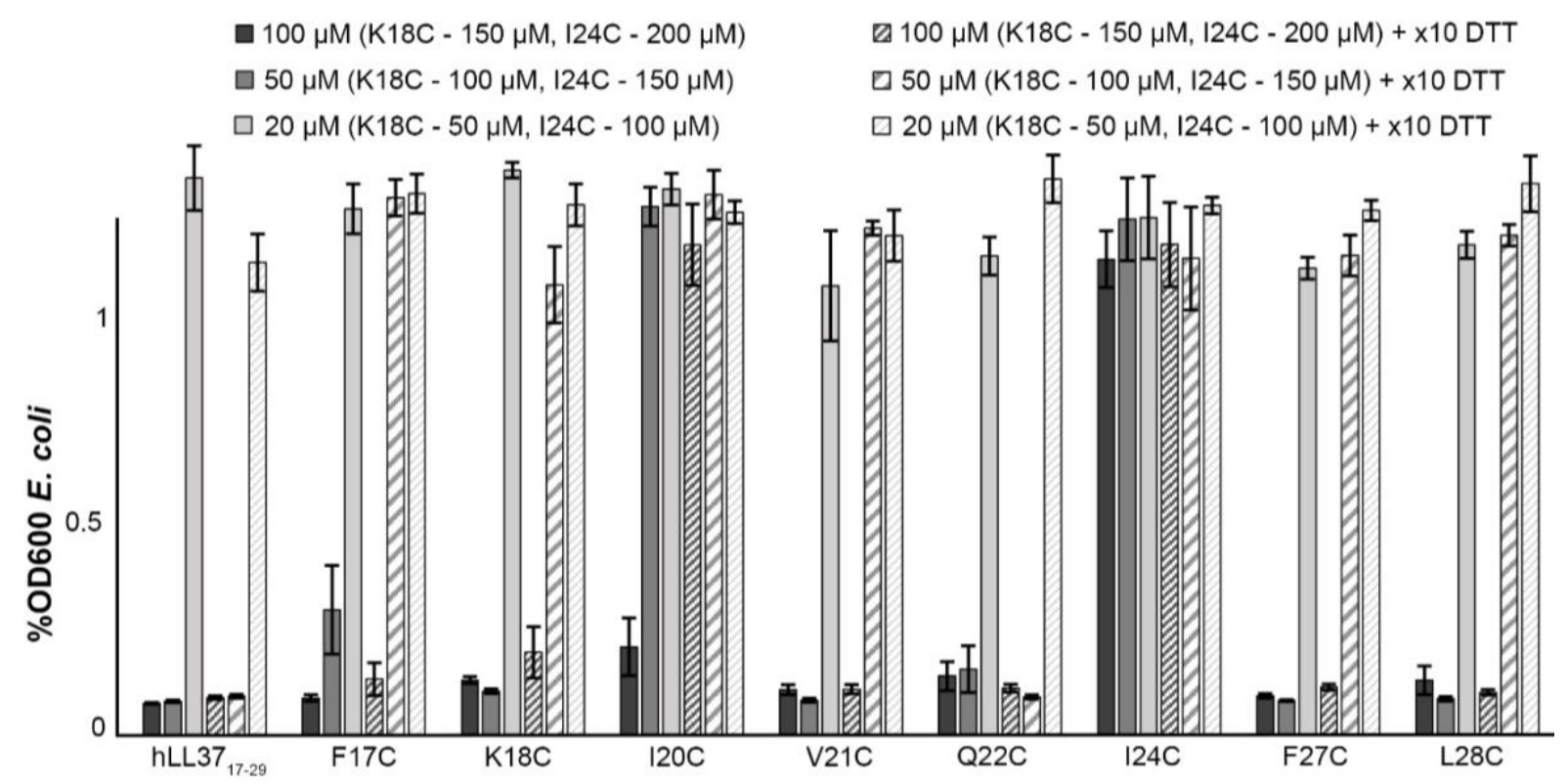

The effect of hLL-37 ${ }_{17-29}$ and its cysteine substitution mutants on $E$. coli bacterial growth was tested in the presence and absence of DTT. Bars show the ratio of $E$. coli growth in the presence of the indicated peptide $(100 \mu \mathrm{M}, 50 \mu \mathrm{M}$ and $20 \mu \mathrm{M})$, compared to the bacterial growth with everything but the peptide. The K18C and I24C mutants, which showed higher MIC values, were tested at the following concentrations $150 \mu \mathrm{M}, 100 \mu \mathrm{M}, 50 \mu \mathrm{M}(\mathrm{K} 18 \mathrm{C})$ and $200 \mu \mathrm{M}, 150 \mu \mathrm{M}$ and $100 \mu \mathrm{M}$ (I24C). DTT was added at x10 molar ratio compared to peptide concentration. The experiments were performed at least three times, each on a different day. Error bars represent the standard deviation of the mean of the averaged triplicates of all biological repeats. 
Figure S8. DTT sensitivity of the $P$. fluorescens inhibitory effect of hLL37 ${ }_{17-29}$ cysteine mutants

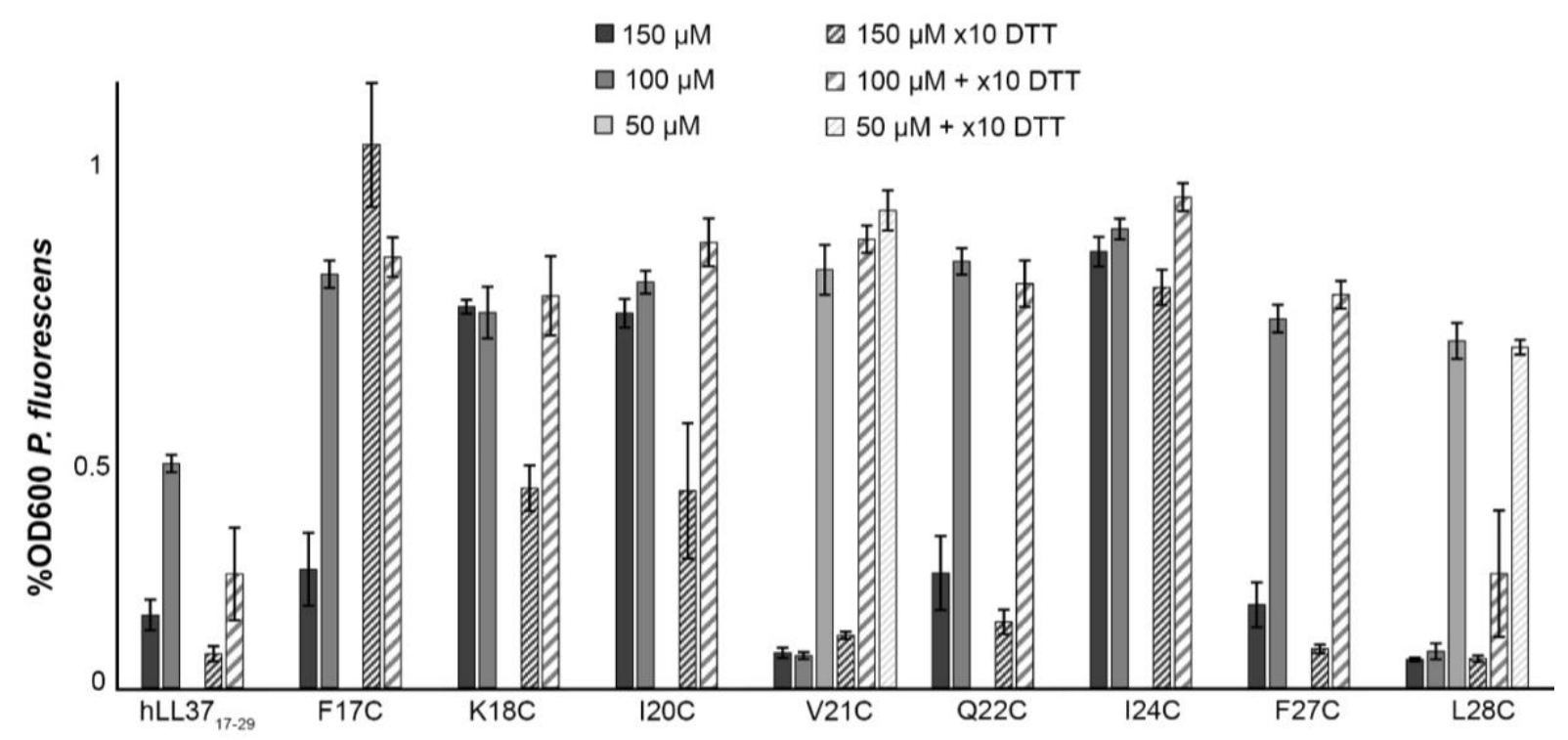

The effect of hLL-37 $17-29$ and its cysteine substitution mutants on $P$. fluorescens bacterial growth was tested in the presence and absence of DTT. Bars show the ratio of $P$. fluorescens growth in the presence of the indicated peptide $(150 \mu \mathrm{M}$ and $100 \mu \mathrm{M})$, compared to the bacterial growth with everything but the peptide. DTT was added at x10 molar ratio compared to peptide concentration. Due to high toxicity of DTT toward P. fluorescens (Figure S10), experiments were performed with only up to $1.5 \mathrm{mM} \mathrm{DTT}$, which allowed peptides to be tested at concentrations up to $150 \mu \mathrm{M}$. The V21C and L28C mutants were tested also at a concentration of $50 \mu \mathrm{M}$ since they displayed lower MICs compared to the other peptides. $\mathrm{K} 18 \mathrm{C}$ and I20C were associated with lower bacterial growth in the presence of DTT, likely due to toxicity of the latter. The experiments were performed at least four times, each on a different day. Error bars represent the standard deviation of the mean of the averaged triplicates of all biological repeats. 
Figure S9. Dose response effect of DTT on growth inhibition activity of F27C against $E$. coli.

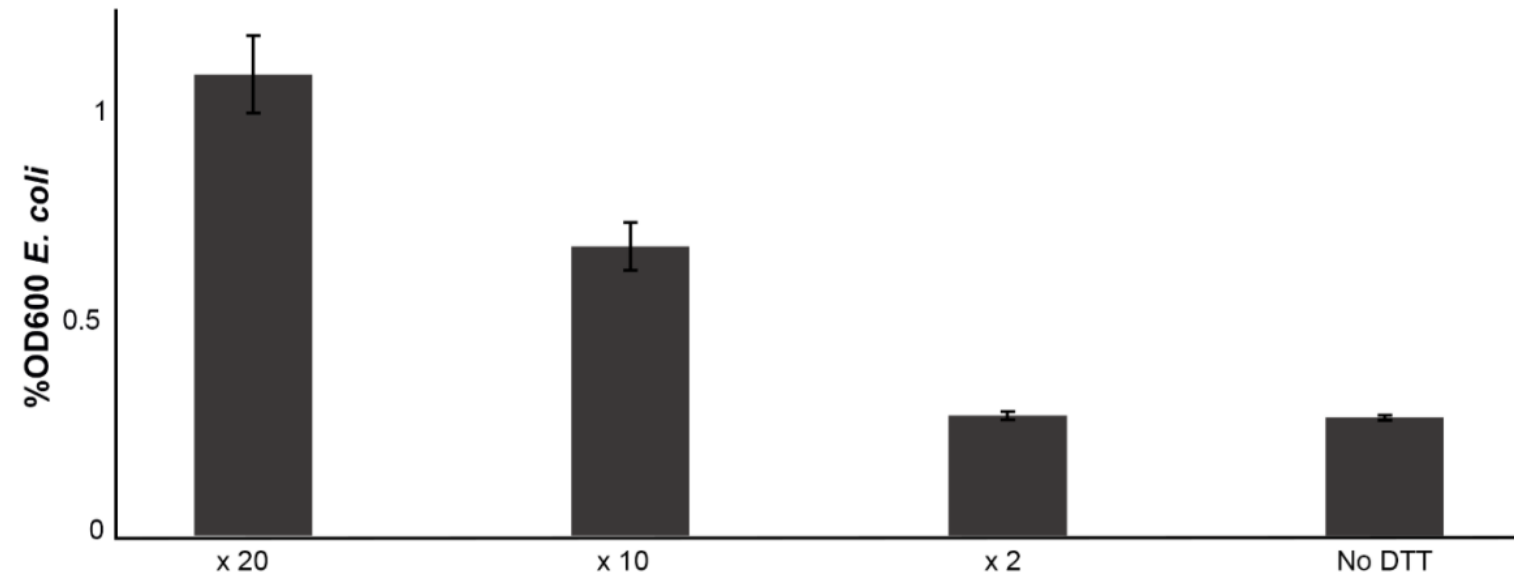

The effect of elevating concentrations of DTT on the growth inhibition activity of F27C against E. coli is shown. Bars show the ratio of $E$. coli growth in the presence of F27C in a fixed concentration of $50 \mu \mathrm{M}$, compared to the bacterial growth with everything but the peptide. DTT was added in elevating molar ratios (x2, x10 and x20). Experiments were performed at least three times, each on a different day. Error bars represent the standard deviation of the mean of the averaged triplicates of all biological repeats. 
Figure S10. DTT direct effect on bacterial growth

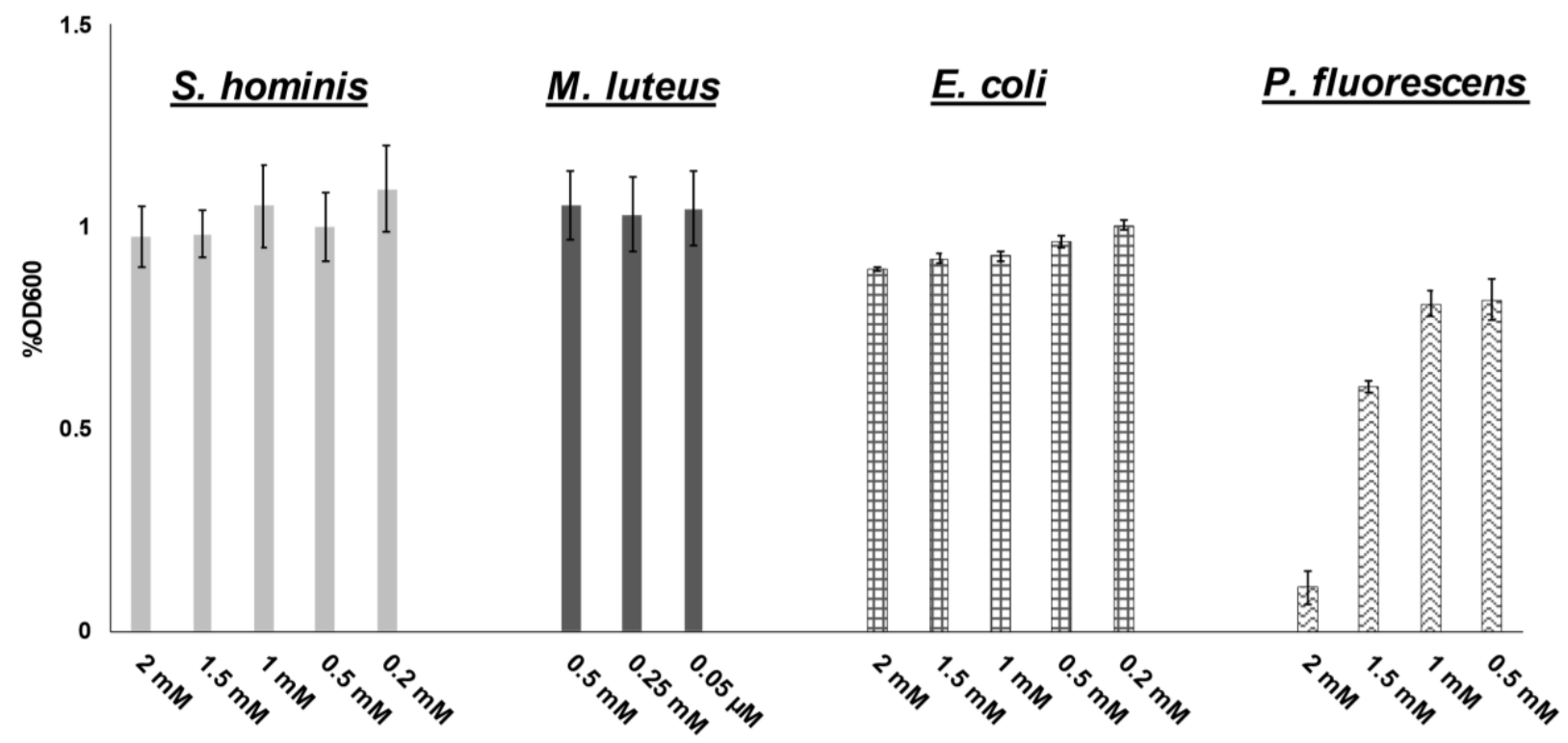

Bars show the ratio of bacterial growth of four species in the presence of different concentrations of DTT as compared to their growth in the absence of DTT. M. luteus was insensitive to DTT concentrations up to $0.5 \mathrm{mM}$. E. coli showed a minor sensitivity to $2 \mathrm{mM}$ DTT ( 90\% growth). P. fluorescens showed the highest sensitivity to DTT, with $10 \%$ and $60 \%$ growth in the presence of $2 \mathrm{mM}$ and $1.5 \mathrm{mM} \mathrm{DTT}$, respectively. The experiments were performed at least four times, each on different days. Error bars indicate the standard error. 


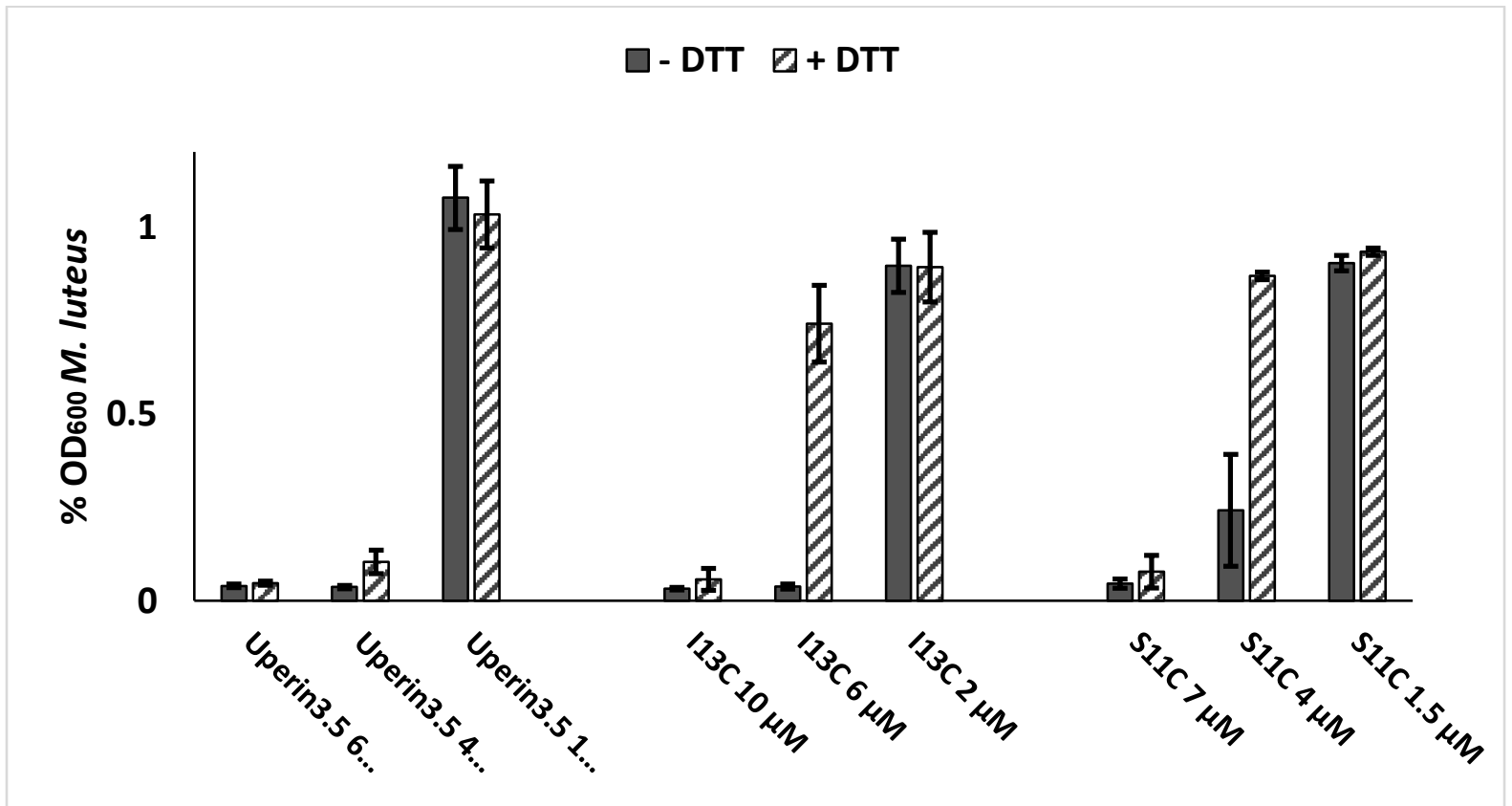

The effect of uperin 3.5 and of its I13C and S11C mutants on M. luteus bacterial growth was tested in the presence and absence of DTT. Bars show the ratio of M. luteus growth in the presence of the indicated peptides, compared to the bacteria growth without the peptide. DTT was added at $\times 10$ molar ratio compared to peptide concentration. The experiments were performed at least three times, on different days. Error bars represent the standard deviation of the mean of all biological repeats. 
Table S1. Data collection and refinement statistics (molecular replacement)

\begin{tabular}{|c|c|}
\hline & Human LL37 ${ }_{17-29}$ I24C mutant \\
\hline PDB accession code & $7 \mathrm{NPQ}$ \\
\hline Beamline & EMBL P14 PETRA III \\
\hline Date & December 17, 2019 \\
\hline \multicolumn{2}{|c|}{ Data collection } \\
\hline Space group & P41212 \\
\hline \multicolumn{2}{|l|}{ Cell dimensions } \\
\hline$a, b, c(\AA)$ & $\begin{array}{lll}34.920 & 34.920 & 44.570 \\
\end{array}$ \\
\hline$\alpha, \beta, \gamma\left(^{\circ}\right)$ & 90.0090 .0090 .00 \\
\hline Wavelength $(\AA)$ & 0.976 \\
\hline Resolution $(\dot{A})$ & $34.92-1.49(1.58-1.49)$ \\
\hline R-factor observed (\%) & $5.3(58.6)$ \\
\hline${ }^{b} R_{\text {meas }}(\%)$ & $5.7(65.3)$ \\
\hline I/ sigma & $19.5(2.3)$ \\
\hline Total reflections & $35816(2826)$ \\
\hline Unique reflections & $4790(648)$ \\
\hline Completeness (\%) & $97.2(84.2)$ \\
\hline Redundancy & $7.5(4.4)$ \\
\hline${ }^{\circ} \mathrm{CC}_{1 / 2}(\%)$ & $99.9(81.9)$ \\
\hline \multicolumn{2}{|c|}{ Refinement } \\
\hline Resolution $(\dot{A})$ & $27.49-1.50(1.54-1.50)$ \\
\hline Completeness (\%) & $99.0(88.6)$ \\
\hline dNo. reflections & $4249(267)$ \\
\hline${ }^{e} R_{\text {work }}(\%)$ & $17.9(46.9)$ \\
\hline$R_{\text {free }}(\%)$ & $19.2(48.3)$ \\
\hline No. atoms & 273 \\
\hline Protein & $\begin{array}{l}120 \text { (Chain A) } \\
137 \text { (Chain B) }\end{array}$ \\
\hline Water & 16 \\
\hline \multicolumn{2}{|l|}{$B$-factors } \\
\hline Protein & $\begin{array}{l}29.2 \text { (Chain A) } \\
26.2 \text { (Chain B) }\end{array}$ \\
\hline Water & 39.3 \\
\hline \multicolumn{2}{|l|}{ R.m.s. deviations } \\
\hline Bond lengths $(\AA \AA A)$ & 0.012 \\
\hline Bond angles $\left({ }^{\circ}\right)$ & 1.946 \\
\hline Clash score $^{1}$ & $3.7\left(96^{\text {th }}\right.$ percentile) \\
\hline Molprobity score ${ }^{1}$ & 1.58 \\
\hline Molprobity percentile $^{1}$ & 79th percentile \\
\hline Number of xtals used for scaling & 1 \\
\hline
\end{tabular}

Values in parentheses are for highest-resolution shell.

(b) $\mathrm{R}$-meas is a redundancy-independent $\mathrm{R}$-factor defined in ${ }^{2}$.

(c) $\mathrm{CC}_{1 / 2}$ is percentage of correlation between intensities from random half-datasets ${ }^{3}$.

(d) Number of reflections corresponds to the working set.

(e) Rwork corresponds to working set. 
Table S2. Calculations of the solvent accessible surface area (SASA) per residue in the crystal structure of hLL-37 ${ }_{17-29}$ I24C compared to hLL-37 ${ }_{17-29}$

\begin{tabular}{|c|c|c|c|c|c|c|c|c|}
\hline & & $\begin{array}{l}1 . \\
\text { Percenta } \\
\text { on an iso } \\
\text { within the } \\
\text { helix bun }\end{array}$ & $\begin{array}{l}\text { SASA } \\
x \text { buried } \\
\text { four- }\end{array}$ & $\begin{array}{l}2 . \\
\text { Percentag } \\
\text { on an isol } \\
\text { in the fibri }\end{array}$ & $\begin{array}{l}\text { e SASA } \\
x \text { buried } \\
\text { embly }\end{array}$ & $\begin{array}{l}3 . \\
\text { Average } \\
\text { percentage } \\
\text { of the } \\
\text { SASA on }\end{array}$ & $\begin{array}{l}4 . \\
\text { Percentage } \\
\text { of the } \\
\text { difference } \\
\text { in the area }\end{array}$ & $\begin{array}{l}5 . \\
\text { Differences } \\
\text { in } \\
\text { percentage } \\
\text { of the area }\end{array}$ \\
\hline Residue & 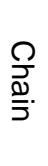 & 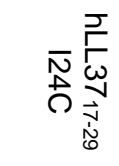 & 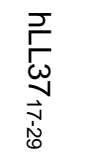 & 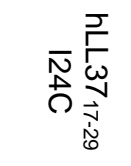 & 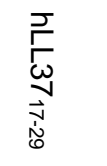 & 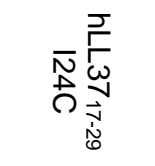 & 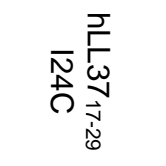 & 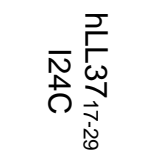 \\
\hline Phe17 & A & $12 \%$ & $40 \%$ & $76 \%$ & $58 \%$ & & $84 \%$ & $64 \%$ \\
\hline & B & $10 \%$ & $38 \%$ & $85 \%$ & $56 \%$ & & $89 \%$ & $75 \%$ \\
\hline Lys18 & A & $0 \%$ & $22 \%$ & $0 \%$ & $37 \%$ & & $0 \%$ & $0 \%$ \\
\hline & B & $0 \%$ & $26 \%$ & $24 \%$ & $43 \%$ & & $100 \%$ & $24 \%$ \\
\hline Arg19 & A & $0 \%$ & $4 \%$ & $41 \%$ & $58 \%$ & & $100 \%$ & $41 \%$ \\
\hline & B & $0 \%$ & $5 \%$ & $51 \%$ & $59 \%$ & & $100 \%$ & $51 \%$ \\
\hline Ile20 & A & $18 \%$ & $54 \%$ & $72 \%$ & $89 \%$ & & $74 \%$ & $54 \%$ \\
\hline & B & $14 \%$ & $63 \%$ & $87 \%$ & $94 \%$ & & $84 \%$ & $73 \%$ \\
\hline Val21 & A & $40 \%$ & $84 \%$ & $80 \%$ & $87 \%$ & & $50 \%$ & $40 \%$ \\
\hline & B & $58 \%$ & $89 \%$ & $96 \%$ & $91 \%$ & & $39 \%$ & $38 \%$ \\
\hline Gln22 & A & $0 \%$ & $0 \%$ & $2 \%$ & $1 \%$ & & $100 \%$ & $2 \%$ \\
\hline & B & $0 \%$ & $0 \%$ & $17 \%$ & $24 \%$ & & $100 \%$ & $17 \%$ \\
\hline Arg23 & A & $0 \%$ & $21 \%$ & $93 \%$ & $77 \%$ & & $100 \%$ & $93 \%$ \\
\hline & B & $0 \%$ & $20 \%$ & $89 \%$ & $80 \%$ & & $100 \%$ & $89 \%$ \\
\hline $\begin{array}{c}\text { Cys24/ } \\
\text { lle24 }\end{array}$ & A & $88 \%$ & $94 \%$ & $100 \%$ & $96 \%$ & $100 \%$ & $12 \%$ & $12 \%$ \\
\hline & B & $83 \%$ & $95 \%$ & $100 \%$ & $95 \%$ & & $17 \%$ & $17 \%$ \\
\hline Lys25 & A & $12 \%$ & $46 \%$ & $80 \%$ & $54 \%$ & & $85 \%$ & $68 \%$ \\
\hline & B & $14 \%$ & $46 \%$ & $82 \%$ & $52 \%$ & & $83 \%$ & $68 \%$ \\
\hline Asp26 & A & $0 \%$ & $0 \%$ & $35 \%$ & $70 \%$ & & $100 \%$ & $35 \%$ \\
\hline & B & $0 \%$ & $0 \%$ & $82 \%$ & $71 \%$ & & $100 \%$ & $82 \%$ \\
\hline Phe27 & A & $54 \%$ & $55 \%$ & $100 \%$ & $83 \%$ & & $46 \%$ & $46 \%$ \\
\hline & B & $50 \%$ & $62 \%$ & $100 \%$ & $87 \%$ & & $50 \%$ & $50 \%$ \\
\hline Leu28 & A & $57 \%$ & $89 \%$ & $99 \%$ & $98 \%$ & & $42 \%$ & $42 \%$ \\
\hline & B & $63 \%$ & $86 \%$ & $96 \%$ & $97 \%$ & $50 \%$ & $34 \%$ & $33 \%$ \\
\hline Arg29 & A & $0 \%$ & $6 \%$ & $73 \%$ & $64 \%$ & & $100 \%$ & $73 \%$ \\
\hline & B & $0 \%$ & $8 \%$ & $85 \%$ & $63 \%$ & & $100 \%$ & $85 \%$ \\
\hline
\end{tabular}


a The number indicated is the percentage of the SASA per residue on an isolated helix versus the SASA of this residue within the dimer in LL37 ${ }_{17-29}$ I24C or the four-helix bundle in LL37 $7_{17-}$ 29. The higher the indicated percentage, the more buried the residue is on an isolated helix by the other helices in the covalently bound dimer in LL37 ${ }_{17-29}$ I24C or in the four-helix bundle in LL37 17-29.

$\mathrm{b}$ The number indicated is the percentage of the SASA per residue on an isolated helix versus the SASA of this residue within the fibrillar assembly. The higher the indicated percentage, the more buried the residue is on an isolated helix by surrounding helices within the fibrillar assembly.

${ }^{c}$ The number indicated is the percentage of the SASA per residue on a dimer in LL37 ${ }_{17-29}$ I24C within the fibrillar assembly.

d The number indicated is calculated by: 100* (column 2 - column 1)/column 2 for LL37 17-29 I24C. The higher the number, the more buried the residue is within the fibrillar assembly compared to the dimer, relative to the extent of the buried area within the assembly.

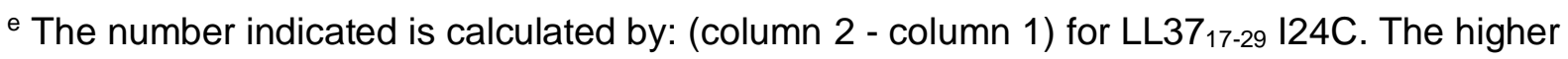
the number, the more buried the residue is within the fibrillar assembly compared to the dimer in absolute percentage numbers. 
Table S3. Sequence and properties of hLL37 $7_{17-29}$ cysteine mutants

a.

\begin{tabular}{|l|l|c|c|c|}
\hline \multicolumn{1}{|c|}{ Peptide } & \multicolumn{1}{|c|}{ Sequence } & $\begin{array}{c}\text { Hydrophobic } \\
\text { moment }\end{array}$ & $\begin{array}{c}\text { Net } \\
\text { charge }\end{array}$ & Hydrophobicity \\
\hline hLL37 17-29 $^{\prime}$ & FKRIVQRIKDFLR & 0.846 & 4 & 0.315 \\
\hline F17C & CKRIVQRIKDFLR & 0.829 & 4 & 0.296 \\
\hline K18C & FCRIVQRIKDFLR & 0.758 & 3 & 0.51 \\
\hline I20C & FKRCVQRIKDFLR & 0.831 & 4 & 0.295 \\
\hline V21C & FKRICQRIKDFLR & 0.858 & 4 & 0.34 \\
\hline Q22C & FKRIVCRIKDFLR & 0.718 & 4 & 0.451 \\
\hline I24C & FKRIVQRCKDFLR & 0.827 & 4 & 0.295 \\
\hline F27C & FKRIVQRIKDCLR & 0.836 & 4 & 0.296 \\
\hline L28C & FKRIVQRIKDFCR & 0.838 & 4 & 0.303 \\
\hline
\end{tabular}

b.

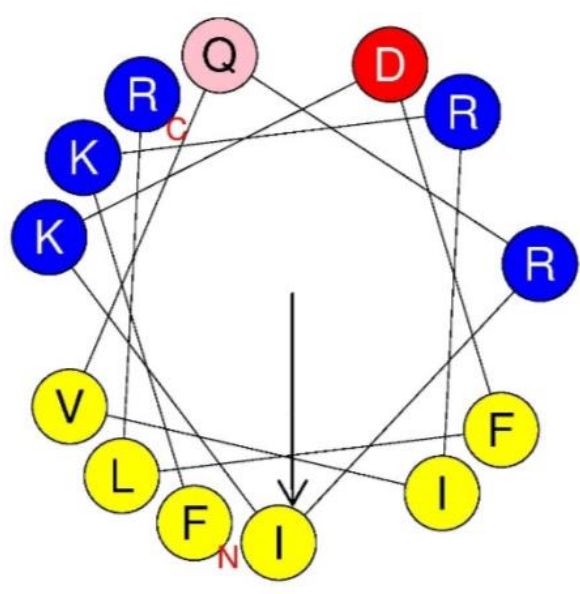

(a) The sequences of hLL37 $17-29$ and its variants bearing cysteine mutants are shown. The cysteine substitutions are in bold font. Physicochemical properties of sequences were calculated using the HeliQuest server ${ }^{4}$. (b) Helical wheel presentation of hLL37 ${ }_{17-29}$, generated by the HeliQuest server ${ }^{4}$. Yellow circles represent nonpolar residues, blue circles represent basic residues, red circles represent acidic residues, and pink circles represent non-charged polar residues. 
Table S4. Particle size and volume distribution of $h L L 37_{17-29}$ and the Q22C and I24C mutants

\begin{tabular}{|c|c|c|c|c|c|}
\hline Peptide & DTT & Subpopulation & $\begin{array}{c}\text { Average } \\
\text { Diameter } \\
\left(\begin{array}{c}\text { Mean } \pm \text { S.E } \\
\mathrm{nm})\end{array}\right.\end{array}$ & $\begin{array}{c}\text { Volume } \\
\text { distribution } \\
\text { (Mean } \pm \text { S.E, } \\
\%)\end{array}$ & $\begin{array}{c}\text { Total particles } \\
\text { average } \\
\text { Diameter } \\
\text { (Mean } \pm \text { S.E } \\
\text { nm) }\end{array}$ \\
\hline \multirow{6}{*}{ hLL37 $17-29$} & \multirow{3}{*}{+} & $0.3-30 \mathrm{~nm}$ & $0 \pm 0$ & $0 \pm 0$ & \multirow{3}{*}{$1053.08 \pm 60.65$} \\
\hline & & $30-3000 \mathrm{~nm}$ & $316.4 \pm 166.2$ & $97.2 \pm 9.57$ & \\
\hline & & $>3000 \mathrm{~nm}$ & $5236 \pm 60.7$ & $2.8 \pm 0.61$ & \\
\hline & \multirow{3}{*}{-} & $0.3-30 \mathrm{~nm}$ & $0 \pm 0$ & $0 \pm 0$ & \multirow{3}{*}{$1053.08 \pm 101.9$} \\
\hline & & $30-3000 \mathrm{~nm}$ & $500.8 \pm 155.2$ & $88.0 \pm 6.65$ & \\
\hline & & $>3000 \mathrm{~nm}$ & $5090.7 \pm 265.2$ & $12.0 \pm 2.67$ & \\
\hline \multirow{6}{*}{ Q22C } & \multirow{3}{*}{+} & $0.3-30 \mathrm{~nm}$ & $0 \pm 0$ & $0 \pm 0$ & \multirow{3}{*}{$759.5 \pm 149.92$} \\
\hline & & $30-3000 \mathrm{~nm}$ & $365.1 \pm 72.3$ & $91.8 \pm 4.94$ & \\
\hline & & $>3000 \mathrm{~nm}$ & $5168.4 \pm 77.6$ & $8.1 \pm 0.78$ & \\
\hline & \multirow{3}{*}{-} & $0.3-30 \mathrm{~nm}$ & $28.4 \pm 0.3$ & $1.1 \pm 0.9$ & \multirow{3}{*}{$890.1 \pm 223.97$} \\
\hline & & $30-3000 \mathrm{~nm}$ & $517.3 \pm 135.8$ & $90.9 \pm 5.55$ & \\
\hline & & $>3000 \mathrm{~nm}$ & $5213.6 \pm 87.8$ & $8.2 \pm 0.89$ & \\
\hline \multirow{6}{*}{ I24C } & \multirow{3}{*}{+} & $0-30 \mathrm{~nm}$ & $1.3 \pm 0.41$ & $100 \pm 11.02$ & \multirow{3}{*}{$1.3 \pm 0.41$} \\
\hline & & $30-3000 \mathrm{~nm}$ & $139.4 \pm 0$ & $0 \pm 0$ & \\
\hline & & $>3000 \mathrm{~nm}$ & $4852.7 \pm 0$ & $0 \pm 0$ & \\
\hline & \multirow{3}{*}{-} & $0-30 \mathrm{~nm}$ & $1.4 \pm 0.3$ & $33.6 \pm 6.18$ & \multirow{3}{*}{$621.7 \pm 56.9$} \\
\hline & & $30-3000 \mathrm{~nm}$ & $338.9 \pm 65.8$ & $57.6 \pm 3.98$ & \\
\hline & & $>3000 \mathrm{~nm}$ & $5123.7 \pm 0.3$ & $8.8 \pm 1.14$ & \\
\hline
\end{tabular}

Dynamic light scattering was used for particle sizing and volume distribution measurements of hLL37 $17-29$ and the Q22C and I24C mutants, in the presence and absence of DTT. Particles size distributions are segmented into three subpopulations: $0.3-30 \mathrm{~nm}, 30-3000 \mathrm{~nm}$ and larger than $3000 \mathrm{~nm}$. The total particles average size in each sample is segmented for each peptide, with or without DTT. The average diameter and percentage of each subpopulation are shown. Experiments were repeated on at least three different days, and five readings of the samples were performed for each measurement. Calculations of the error values are described in the Methods section. 
Table S5. Sequences, physicochemical properties, bacteriostatic activity and DTT sensitivity of uperin 3.5 and its single-point cysteine mutants.

a.

\begin{tabular}{|l|l|c|c|c|}
\hline \multicolumn{1}{|c|}{ Peptide } & Sequence & $\begin{array}{c}\text { Hydrophobic } \\
\text { moment }\end{array}$ & $\begin{array}{c}\text { Net } \\
\text { charge }\end{array}$ & Hydrophobicity \\
\hline Uperin 3.5 & GVGDLIRKAVSVIKNIV-NH2 & 0.637 & 3 & 0.464 \\
\hline S11C & GVGDLIRKAVCVIKNIV-NH2 & 0.544 & 3 & 0.557 \\
\hline I13C & GVGDLIRKAVSVCKNIV-NH2 & 0.623 & 3 & 0.449 \\
\hline
\end{tabular}

b.

\begin{tabular}{|c|c|c|}
\hline & $\begin{array}{c}\text { MIC } \\
(\mu \mathrm{M})\end{array}$ & $\begin{array}{c}\text { DTT } \\
\text { sensitivity }\end{array}$ \\
\hline Uperin 3.5 & 4 & - \\
\hline I13C & $7 \pm 0.3$ & + \\
\hline S11C & $5 \pm 0.8$ & + \\
\hline
\end{tabular}

(a) The sequences of uperin 3.5, and its cysteine mutants are shown. The cysteine substitutions are in bold font. Physicochemical properties of sequences were calculated using the HeliQuest server ${ }^{4}$. (b) Inhibition of growth of $M$. luteus by uperin 3.5 and its two cysteine mutants is indicated by the MIC values. The MIC of the natural uperin 3.5 was determined in ref $^{5}$. The DTT effect on the growth inhibition is marked by + or -, as presented in figure 4 . The experiments were performed at least three times, each on a different day. 
Table S6. sahAMPs with an odd number or single residues of cysteines are particularly rare

\begin{tabular}{|c|c|c|c|}
\hline Average $\mu \mathrm{H}$ of short AMPs predicted as helical & \multicolumn{3}{|c|}{0.378} \\
\hline \multicolumn{4}{|l|}{ Number of: } \\
\hline AMPs (in the CAMP $_{\mathrm{R} 3}$ database ${ }^{6}<100 \mathrm{aa}$ ) & \multicolumn{3}{|l|}{2300} \\
\hline Short AMPs (<40aa) & \multicolumn{3}{|l|}{1808} \\
\hline Short helical AMPs & \multicolumn{3}{|l|}{1150} \\
\hline sahAMPs - Short helical and amphipathic AMPs (with $\mu \mathrm{H}>$ avg) & \multicolumn{3}{|l|}{553} \\
\hline & Cys & Tyr & Arg \\
\hline Frequency of amino acid ' $X$ ' in short AMPs & 6 & 1.9 & 5.9 \\
\hline \multicolumn{4}{|l|}{ Number of: } \\
\hline AMPs containing residue ' $X$ ' & 754 & 522 & 834 \\
\hline Short AMPs containing a single residue ' $X$ ' & 63 & 347 & 294 \\
\hline Short helical AMPs containing a single residue ' $X$ ' & 27 & 152 & 174 \\
\hline $\begin{array}{l}\text { Short helical and amphipathic AMPs (sahAMPs) containing a single } \\
\text { residue ' } X \text { ' }\end{array}$ & 7 & 38 & 81 \\
\hline AMPs containing an odd number of residue ' $X$ ' & 125 & 394 & 534 \\
\hline Short helical AMPs containing an odd number of residue ' $X$ ' & 44 & 161 & 275 \\
\hline $\begin{array}{l}\text { Short helical and amphipathic AMPs (sahAMPs) containing an odd } \\
\text { number of residue ' } X \text { ' }\end{array}$ & 8 & 38 & 117 \\
\hline
\end{tabular}

Numerical statistical analysis of the number of AMPs from the $\mathrm{CAMP}_{\mathrm{R} 3}$ database ${ }^{6}$ devided in four groups: 1) shorter than 100 amino acids (aa)), 2) shorter than 40aa, 3) short and helical, and 4) short, helical, and amphipathic AMPs (sahAMPs). Helicity was predicted by the Jpred server $^{7}$. Amphipathicity was evaluated using the hydrophobic moment $(\mu \mathrm{H})$ of the helix, with amphipathic sequences defined as those with $\mu \mathrm{H}$ larger than the average of all short and helical AMPs. 
Table S7. Identified sahAMPs containing single cysteine residue

\begin{tabular}{|c|c|c|c|}
\hline CampID & UniProt & Sequence & $\begin{array}{l}\text { Hydrophobic } \\
\text { moment }\end{array}$ \\
\hline CAMPSQ7 & P84868 & KTCENLADTY & 0.65 \\
\hline CAMPSQ519 & P84200 & KTCENLADDY & 0.65 \\
\hline CAMPSQ3841 & & IGGYCSWLRL & 0.4 \\
\hline CAMPSQ8187* $^{*}$ & & KRWWKWWRRC & 0.98 \\
\hline CAMPSQ615 & P39084 & FLGGLIKIVPAMICAVTKK & 0.43 \\
\hline CAMPSQ1883 & P86013 & AS॥KTTUKVSKAVCKTLTC|CTGSCSNCK & 0.39 \\
\hline CAMPSQ198 & P49931 & GRFBRLRKKTRKRLKKJGKVLKWIPPIVGSIPLGCG & 0.43 \\
\hline CAMPSQ2768 & P49931 & VGRERRLRKKTRKRLKKIGKVLKWIPPIVGSIPLGCG & 0.42 \\
\hline
\end{tabular}

Sequences containing a single cysteine residue were filtered from the $\mathrm{CAMP}_{\mathrm{R} 3}$ database ${ }^{6}$ after selecting only experimental validated AMPs which are short, helical and amphipathic sequences (as described in the Methods section). Underlines beneath sequences segments indicate the helical motifs predicted (as described in the Methods section).

*Synthetic sequence

\section{References}

(1) Chen, V. B.; Arendall, W. B., 3rd; Headd, J. J.; Keedy, D. A.; Immormino, R. M.; Kapral, G. J.; Murray, L. W.; Richardson, J. S.; Richardson, D. C. MolProbity: all-atom structure validation for macromolecular crystallography. Acta Crystallogr., Sect. D: Biol. Crystallogr 2010, 66 (Pt 1), 12-21. DOI: 10.1107/s0907444909042073.

(2) Diederichs, K.; Karplus, P. A. Improved R-factors for diffraction data analysis in macromolecular crystallography. Nat. Struct. Biol. 1997, 4 (4), 269-275. DOI: 10.1038/nsb0497-269.

(3) Karplus, P. A.; Diederichs, K. Linking crystallographic model and data quality. Science 2012, 336 (6084), 1030-1033. DOI: 10.1126/science.1218231.

(4) Gautier, R.; Douguet, D.; Antonny, B.; Drin, G. HELIQUEST: a web server to screen sequences with specific alpha-helical properties. Bioinformatics (Oxford, England) 2008, 24 (18), 2101-2102. DOI: 10.1093/bioinformatics/btn392.

(5) Salinas, N.; Tayeb-Fligelman, E.; Sammito, M. D.; Bloch, D.; Jelinek, R.; Noy, D.; Usón, I.; Landau, M. The amphibian antimicrobial peptide uperin 3.5 is a cross- $\alpha /$ cross- $\beta$ chameleon functional amyloid. Proc. Natl. Acad. Sci. U. S. A. 2021, 118 (3). DOI: 10.1073/pnas.2014442118. 
(6) Waghu, F. H.; Barai, R. S.; Gurung, P.; Idicula-Thomas, S. CAMPR3: a database on sequences, structures and signatures of antimicrobial peptides. Nucleic Acids Res. 2016, 44 (D1), D1094-1097. DOI: 10.1093/nar/gkv1051.

(7) Drozdetskiy, A.; Cole, C.; Procter, J.; Barton, G. J. JPred4: a protein secondary structure prediction server. Nucleic Acids Res. 2015, 43 (W1), W389-394. DOI: 10.1093/nar/gkv332. 